\title{
Assessing attachment to parents and peers in middle childhood: Psychometric studies of the Portuguese version of People in My Life questionnaire
}

\author{
Helena Moreira $\bullet$ Ana Fonseca $\bullet$ Maria Cristina Canavarro \\ Cognitive-Behavioural Center for Research and Intervention, University of Coimbra, \\ Coimbra, Portugal
}

Funding: This work was supported by the Portuguese Foundation for Science and

Technology under Grant SFRH/BPD/70063/2010

\section{Corresponding author:}

H. Moreira

Cognitive-Behavioural Center for Research and Intervention, Faculty of Psychology and Educational Sciences, University of Coimbra.

Rua do Colégio Novo, Apartado 6153, 3001-802 Coimbra, Portugal.

e-mail: hmoreira@fpce.uc.pt

\section{Cite as:}

Moreira, H., Fonseca, A., \& Canavarro, M. C. (2017). Assessing attachment to parents and peers among children and adolescents: Validation of the Portuguese version of the People in My Life. Journal of Child and Family Studies, 26(5), 13181333. doi:10.1007/s10826-017-0654-3

URL: http://link.springer.com/article/10.1007/s10826-017-0654-3 
Portuguese version of PIML

8 children and replicated in the sample of adolescents using confirmatory factor analyses. The Portuguese version

9 of the PIML showed adequate internal consistency and correlated as expected with measures of intra- and interpersonal functioning (internalizing and externalizing problems, prosocial behavior, quality of life, self-

11 compassion, and emotion regulation strategies). The PIML proved to be a psychometrically robust measure of children's representations of their relationships with parents and peers, representing an important advance in the measurement of attachment in middle childhood.

14 Keywords: PIML; attachment; middle childhood; parents; peers. 
Portuguese version of PIML

Assessing attachment to parents and peers in middle childhood: Psychometric studies of the Portuguese

\section{version of People in My Life questionnaire}

\section{Introduction}

According to the attachment theory (Bowlby, 1969/1982), all infants are born with a behavioral attachment system that has the biological function of protecting the individual in threatening and adverse circumstances. In these circumstances, the attachment system is automatically activated, leading the child to elicit care and seek the proximity of a stronger and wiser figure that could protect and help him or her restore a sense of security (Mikulincer \& Shaver, 2007). Through repeated interactions with attachment figures, usually the parents during early childhood but also other figures such as peers during childhood and adolescence, children gradually develop internal working models (IWM) or mental representations about one's own worth of care and love (IWM of self) and the availability and responsivity of an attachment figure in times of need (IWM of others; Bretherton \& Munholland, 1999). If attachment figures are consistently available and responsive, a secure bond with these figures is established and the child develops IWM of self as worthy of care and love and of others as trustworthy and consistently available. However, if these figures are not available and responsive or are inconsistently responsive, an insecure attachment pattern may develop, and the child learns that he or she is not worth of love and care and that others are unavailable and unreliable (Ainsworth, 1979; Ainsworth, Blehar, Waters, \& Wall, 1978).

Several assessment instruments have been developed to assess attachment patterns or IWM in different developmental periods. Attachment patterns in infancy and early childhood have been assessed mainly through controlled observational methods (Ainsworth et al., 1978; Crittenden, 1992), naturalistic observational methods (Waters, 1995) or representational methods (Kaplan \& Main, 1986; Slough \& Greenberg, 1990). During adolescence, it has been proposed that the affective-cognitive component of attachment (i.e., the IWM) could be reliably measured through self-report questionnaires (Wilson \& Wilkinson, 2012). In addition, given the central role that peer relationships assume in adolescents' lives as sources of psychological security, it has been suggested that measuring attachment to peers is also relevant during this developmental stage (Armsden \& Greenberg, 1987). Therefore, several self-report questionnaires were developed to measure attachment to parents and peers in adolescence, such as the Adolescent Attachment Questionnaire (West, Rose, Spreng, SheldonKeller, \& Adam, 1998) and the Inventory of Parent and Peer Attachment (IPPA; Armsden \& Greenberg, 1987). Surprisingly, there is a dearth of adequate measures for middle childhood. To overcome this limitation, Cook, 
Portuguese version of PIML

1 Greenberg, and Kusche (1995) developed the People in My Life questionnaire (PIML) to assess children's representations of the relationships with their parents and peers during this developmental phase.

The PIML can be considered as an adaption of the IPPA for use in middle childhood. In fact, the PIML questionnaire was developed through the elimination or adaptation of the IPPA items (linguistic changes) with the purpose of obtaining a questionnaire appropriate to the comprehension level of children aged between 10 to 12 years. The IPPA is the most widely used self-report questionnaire of adolescents' attachment representations and was designed for adolescents aged between 12 and 19 years. It is composed of two scales to assess adolescents' representations of the relationship with their parents and friends (the Parents Attachment Scale and the Peers Attachment Scale) and, therefore, the extent to which parents and peers are perceived as secure attachment figures. According to Armsden and Greenberg (1987), adolescents' representations or IWM could be tapped through the assessment of the "positive affective/cognitive experience of trust in the accessibility and responsiveness of attachment figures" and the "negative affective/cognitive experiences of anger and hopelessness resulting from unresponsive or inconsistently responsive attachment figures” (p. 431). Therefore, both the Parents and Peers scales include three subscales: (1) Trust, which assesses the degree of mutual respect and trust in the relationship; (2) Communication, which assesses the quality of verbal communication with parents and friends (both assessing positive affective-cognitive experiences in the relationship with parents and peers); and (3) Alienation, which assesses negative affective-cognitive experiences in the relationship with parents and peers, such as feelings of anger, isolation, and alienation. Considering the strong intercorrelations between the three subscales, the authors also proposed the calculation of a total score of attachment (in)security, which could be obtained by summing all items after reverse-coding the negative items in the alienation subscale. Armsden and Greenberg (1987) proposed that high levels of trust and communication and low levels of alienation would characterize a secure attachment, whereas low levels of trust and communication and high levels of alienation would classify insecure attachments (regardless of the type of insecurity).

Like the IPPA, the PIML measures positive and negative affective-cognitive experiences in relationships with parents and peers in terms of the same three dimensions: Trust, Communication, and Alienation. The Peers Attachment Scale additionally includes a Delinquency subscale designed to assess the delinquent behavior of the children's friends, which allows for the examination of the discriminant validity of the questionnaire (Cook et al., 1995). The original version of the PIML included four scales assessing attachment to parents, peers, teachers, and school. Nevertheless, only the Parents and Peers scales were later analyzed in the psychometric study of this measure (Ridenour, Greenberg, \& Cook, 2006). In that study, confirmatory factor 
Portuguese version of PIML

1 analyses demonstrated that the PIML structure is consistent with the IPPA structure. Specifically, the authors

2 found that the factor structure that better fit the data in both scales was the one that included a second-order

3 factor of attachment (Parents Attachment and Peers Attachment) and three or four first-order factors (Trust,

4 Communication, and Alienation in the Parents scale; Trust, Communication, Alienation, and Delinquency in the

5 Peers scale). Notably, although the Delinquency subscale was included in the factor analyses, the authors

6 emphasized that this subscale is "largely independent of peer attachment" (Ridenour et al., 2006, p. 1050) and

7 clarified that they only included it in the analyses because the subscale was originally part of the questionnaire.

8 Consistently with the factor structure, it is possible to obtain separate scores for each subscale, as well as a total

9 attachment score for each scale.

10 Concerning reliability, the Cronbach's alphas for the total scores of PIML and for the Trust and

11 Communication subscales were above .70, although they were slightly below this threshold for the Alienation

12 and Delinquency subscales. With respect to the validity analyses, significant correlations in the expected

13 directions were found between the PIML subscales and measures of internalizing and externalizing

14 symptomatology, depressive symptomatology, competences (frustration tolerance, peer sociability, assertiveness,

15 and task orientation), and delinquent behavior. In addition, differences in the PIML scores between African

16 Americans and Caucasians; children in regular school classes and those in special education classes; and boys

17 and girls were analyzed. No significant differences were found between ethnic groups, but children recruited in

18 special education classes reported, in general, more negative experiences in the relationship with parents and

19 peers than children recruited in regular schools. Additionally, boys reported more trust in the relationship with

20 their parents but less communication and overall attachment to peers than girls. In spite of the differences in

21 some subscales, the authors argued that the factor structure of PIML is generalizable across ethnicities,

22 educational settings, and genders (Ridenour et al., 2006).

23 Validation studies in different cultures are essential to further exploring the reliability and validity of

24 this questionnaire and its cross-cultural adequacy. These studies are crucial to establishing the psychometric

25 robustness of the questionnaire and to enable its adequate utilization in other populations. In this study, we

26 present the validation studies of the Portuguese version of the PIML. Therefore, two different studies were

27 conducted to (1) test the factor structure of the PIML in a sample of children, explore its reliability, and construct

28 validity; and to (2) cross-validate the factor structure of the PIML in a sample of adolescents and further examine

29 its reliability and construct validity. The provision of a well-validated measure that can be used reliably among 
Portuguese version of PIML

1 Portuguese-speaking children will represent an advancement in the measurement of attachment in middle 列 childhood.

\section{Study 1}

In Study 1, we tested whether the factor structure of the Parents Attachment and Peers Attachment scales could be represented, as in the original measure, by a hierarchical structure composed of a second-order factor of global attachment and three or four lower order factors (Trust, Communication, and Alienation in the Parents scale; Trust, Communication, Alienation, and Delinquency in the Peers scale). Similar to the original PIML structure, the Parents Attachment Scale and the Peers Attachment Scale were considered two independent constructs. Second, we investigated the reliability of the PIML scales and present the item analyses. Finally, we aimed to further explore the construct validity of the PIML by examining gender differences in PIML scores and by analyzing correlations with measures of intra- and interpersonal functioning (internalizing and externalizing problems, prosocial behavior, quality of life), distinct constructs that are expected to be associated with children's attachment (convergent validity).

\section{Participants}

\section{Method}

The sample was composed of 314 children ( $50.6 \%$ boys and $49.4 \%$ girls), aged between 8 and 12 years $(M=9.64 ; S D=1.43)$. The majority of children $(n=203 ; 64.6 \%)$ were in the $1^{\text {st }}$ cycle of basic education (grades $1-4), 66(21.0 \%)$ were in $2^{\text {nd }}$ cycle (grades 5-6), and 45 (14.3\%) were in the $3^{\text {rd }}$ cycle (grade 7$)$. The inclusion criteria were to be aged between 8 and 12 years, to be able to understand and autonomously answer the questionnaires, and to have no serious mental illness or developmental delay.

\section{Procedures}

The sample was collected in public schools $(n=282)$ and in the general community $(n=32)$ in the north and central regions of Portugal. Authorization for sample collection was obtained from the National Commission for Data Protection and from the Board of Directors of three School Units. After authorization was received, several classes of the $1^{\text {st }}, 2^{\text {nd }}$, and $3^{\text {rd }}$ cycles of basic education (grades 1 to 7 ) from different schools of the three school units were randomly selected. Teachers were contacted by the researchers and invited to collaborate in the study by assisting the researchers in explaining and distributing the assessment batteries in class. Children were instructed to give their parents the envelope containing a letter explaining the study, the informed consent form, and the questionnaires. The subset of 32 children from the general community were invited to participate through the researchers' acquaintances. In both cases, the questionnaires were completed at 
Portuguese version of PIML

1 home and returned approximately one week later. Parents were informed in the letter that they could assist their children in understanding the items of the questionnaires but could not influence their answers. Informed consent was obtained from all parents, and informal assent was obtained from children. Participation in the study was voluntary and no monetary or other compensation was given to the participants.

A subsample of 177 children (145 collected in schools and 32 from the general community) completed additional measures of psychological functioning, prosocial behavior, and quality of life. These children (57.1\% boys) had a mean age of 9.38 years $(S D=1.27$; range: $8-12)$. The remaining children returned the assessment battery incomplete.

\section{Measures}

People in My Life questionnaire. The original version of the People in My Life questionnaire (Ridenour et al., 2006) has two scales (Parents Attachment Scale, which has 21 items; and Peers Attachment Scale, which has 26 items), each of which comprises three dimensions: (1) Trust (e.g., "My parents respect my feelings"; "My friends accept me as I am"); (2) Communication (e.g., "I talk to my parents when I am having a problem"; "I share my thoughts and feelings with my friends"); and (3) Alienation (e.g., "I feel angry with my parents"; "I get upset easily with my friends"). The Peers Scale also includes a Delinquency subscale (3 items) that assesses children's agreement with the delinquent behavior of their friends (e.g., "If one of my friends asked me to skip school, I would do it"). The PIML items are answered using a four-item Likert scale that ranges from 1 (almost never or never true) to 4 (almost always or always true), and each subscale score consists of the sum of the items, with high scores indicating high levels of Trust, Communication, Alienation, and Delinquency. In both scales (Parents Attachment and of Peers Attachment), it is also possible to obtain a global score of attachment by summing all items, after reverse-coding the items from the Alienation subscale.

The Portuguese version of the PIML was developed through a forward-backward translation procedure. After obtaining authorization from the authors of the original version to translate and validate the questionnaire, two authors of the Portuguese version independently translated the items of the PIML. The two translated versions were compared, and after discussing and analyzing their similarities and differences, the first Portuguese version was obtained. This preliminary version was subsequently translated back into English by a researcher in psychology who is fluent in English and was not familiar with the questionnaire. Finally, the original and the back-translated versions were compared, and translation difficulties were analyzed and resolved between translators to obtain a comprehensible instrument that was conceptually consistent with the original. 
Portuguese version of PIML

Strengths and Difficulties Questionnaire. The self-report version of the Strengths and Difficulties

Questionnaire (SDQ; Fleitlich, Loureiro, Fonseca, \& Gaspar, 2005; A. Goodman, Lamping, \& Ploubidis, 2010;

R. Goodman, 2001) is a brief screening questionnaire for assessing the prosocial behavior and psychological functioning of children and adolescents. It has 26 items distributed over three subscales: Prosocial Behavior (e.g., "I try to be nice to other people. I care about their feelings"), Externalizing Problems (e.g., "I get very angry and often lose my temper", "I get restless, I cannot sit still for long”) and Internalizing Problems (e.g., "I have one good friend or more", "I worry a lot"). The questionnaire is answered using a Likert-type response scale ranging from 0 (not true) to 2 (certainly true), with high scores indicating internalizing/externalizing problems and high levels of prosocial behavior. In the current study, Cronbach's alphas were .66 (internalizing problems), .73 (externalizing problems), and .63 (prosocial behavior). Cronbach's alphas in the original version were .66 (internalizing and prosocial behavior subscales) and .76 (externalizing subscale). Confirmatory factor analyses confirmed the second-order internalizing and externalizing factors (A. Goodman et al., 2010). The Portuguese version has evidenced adequate internal consistency across different samples of children and adolescents (e.g. Gouveia, Frontini, Canavarro, \& Moreira, 2014; Moreira et al., 2013).

KIDSCREEN-10 index. The self-report version of the KIDSCREEN-10 index (Matos, Gaspar, \& Simões, 2012; Ravens-Sieberer et al., 2010) was used to assess children's perception of their quality of life (e.g., "Have you felt fit and well?"; "Have you had fun with your friends?”). This 10-item unidimensional questionnaire is answered using a five-point Likert scale that ranges from 1 (never; not at all) to 5 (always; extremely), with high scores indicating good quality of life. In the present sample, the Cronbach's alpha was .68. The original version of the KIDSCREEN-10 index (Ravens-Sieberer et al., 2010) presented adequate reliability (Cronbach's $\alpha=.82)$ and temporal stability $(\mathrm{ICC}=.70)$ and demonstrated good criterion and construct validity (convergent, discriminant, and known-groups). The validation study of the Portuguese version (Matos et al. 2012) confirmed the original unidimensional structure and showed adequate reliability (Cronbach's $\alpha=.78$ ).

\section{Data Analyses}

The factor structure of the Parents and Peers scales of the Portuguese version of the PIML was tested by confirmatory factor analyses (CFA) using AMOS® 20 with maximum likelihood estimation. Before conducting the CFA, basic assumptions were investigated. The presence of outliers was determined by examining leverage indices and Mahalanobis distance $\left(\mathrm{D}^{2}\right)$ statistic for all participants. A leverage score five times greater than the sample leverage value (Brown, 2006) and a $\mathrm{D}^{2}$ value that particularly departs from all the other $\mathrm{D}^{2}$ values $(\mathrm{Byrne}$, 2010) were considered as an outlier. Only two outlier cases were detected and, therefore, eliminated from the 
Portuguese version of PIML

sample, which resulted in a final sample of 314 children. Collinearity was examined through the inspection of tolerance and VIF values. Considering tolerance values $<.10$ and VIF values $>10.0$ as suggestive of extreme multivariate collinearity (Kline, 2011), no evidence of collinearity was detected. Normality was assessed through examination of skewness and kurtosis of each individual item and the data distribution was considered nonnormal if the values of skewness and kurtosis were above 3 and 10, respectively (Kline, 2011). Missing data were infrequent (most items were completed by all participants and no item presented more than $0.9 \%$ of missing cases) and were managed by mean substitution (missing scores were replaced by the mean of the subscale of a particular item). The CFA was conducted separately for the Parents and Peers Attachment scales. For both scales, a second-order model with three (Parents Scale) or four (Peers Scale) first-order factors and a single higher order factor of attachment was tested. Of note, item 12 of the Parents scale ("When I am away from home, my parents know where I am and who I am with”) was excluded from all the analyses because this item was also excluded in the original factor analyses (Ridenour et al., 2006). The main goodness-of-fit indices were considered to evaluate the overall model fit. Because the chi-square index $\left(\chi^{2}\right)$ is very sensitive to sample size and may overestimate the lack of model fit, the assessment of fit was based on three additional indicators: the comparative fit index (CFI), the root-mean-square error of approximation (RMSEA), and the standardized rootmean-square residual (SRMR). Criteria for good model fit were a non-significant $\chi^{2}(p>.05), \mathrm{CFI} \geq .95$, RMSEA $\leq .06$, and SRMR $\leq .08$; criteria for acceptable fit were CFI $\geq .90$, RMSEA $\leq .08$, and SRMR $\leq .10$ (Browne \& Cudeck, 1993; Hu \& Bentler, 1999).

To explore the internal consistency of the PIML, Cronbach's alphas were obtained for each subscale and for the total score of each scale. Correlations between the PIML subscales and total scores were also analyzed. Differences between boys and girls in the PIML subscales and total score were analyzed through multivariate and univariate analyses of variance, respectively. Correlations with measures that assess constructs distinct from attachment but that are expected to be related to children's attachment were analyzed to explore the convergent validity of the PIML.

\section{Results}

Because two different data collection procedures were employed, differences in sociodemographic variables and in PIML subscales between children who were recruited in school settings and in the general community were analyzed. The same proportions of boys and girls were collected in the two settings, $\chi^{2}(1)=$ $0.45, p=.503$, and no significant differences were found in children's age, $F(1,312)=3.18, p=.076$. In addition, no significant differences were found in the Parents subscales, Wilk's lambda $=0.996, F(3,310)=0.44$, 
Portuguese version of PIML

$1 p=.726, \eta_{\mathrm{p}}^{2}=.004$, or in the Peers subscales, Wilk's lambda $=0.994, F(3,310)=0.65, p=.581, \eta_{\mathrm{p}}^{2}=.006$.

2 Therefore, the two groups were analyzed together in the subsequent analyses.

3 Confirmatory Factor Analysis

In the Parents scale, the analysis of skewness and kurtosis values suggested that none of the items were significantly skewed or highly kurtotic. Skewness values ranged from -2.76 (item 5) to 2.51 (item 19) and kurtosis values ranged from -1.30 (item 15) to 8.61 (item 5). As presented in Table 1, the model failed to present an adequate fit to the data. Therefore, modification indices were examined, suggesting that the errors belonging to items 6 and 7, 6 and 20,8 and 10,9 and 11, and 16 and 17 might be correlated. Because these pairs of items had similar content and belonged to the same factors, their measurement errors were allowed to correlate (Byrne, 2010). The re-specified model (Model 2) had an acceptable fit to the data, which was significantly better than the fit of the original model $\left[\Delta \chi^{2}(5)=68.92, p<.001\right]$. The three first-order factors loaded significantly on the general Parents attachment factor and all standardized factor loadings for the items were significant $(p<.001)$, ranging from .30 to .77 (see Figure 1). In the Peers scale, the examination of the skewness and kurtosis values suggested that items $23(\mathrm{Sk}=$ $4.64 ; \mathrm{Ks}=21.49)$ and $24(\mathrm{Sk}=4.24 ; \mathrm{Ks}=17.84)$ of the Delinquency scale were significantly skewed and highly kurtotic. In addition, the Delinquency subscale did not load significantly on the general Peer Attachment factor, $(b=-.03 ; p=.072)$. Because this subscale is not theoretically related to the construct of attachment to peers, a model excluding the Delinquency subscale was examined (Model 1). As presented in Table 1, the model failed to present an adequate fit to the data. Therefore, modification indices were examined, suggesting that the errors belonging to items 1 and 2, 2 and 4, 6 and 7, 9 and 11, and 12 and 19 might be correlated. The re-specified model (Model 2) had an acceptable fit to the data, which was significantly better than the fit of the original model $\left[\Delta \chi^{2}(5)=117.18, p<.001\right]$. All first-order factors loaded significantly on the general Peer Attachment Scale and all standardized factor loadings for the items were significant $(p<.001)$, ranging from .20 to .79 (see Figure 2).

(Insert Table 1 and Figures 1 and 2)

Reliability, Item Analyses, and Intercorrelations between the PIML Subscales

As presented in Tables 2 and 3, the Trust and Communication subscales presented adequate internal consistency in both scales (Cronbach alpha's coefficients were above .73). However, the Alienation subscale presented an alpha coefficient below the recommendations in both scales $(\alpha=.66)$. The elimination of each individual item of the corresponding subscale did not contribute to an increase in the subscale's alpha coefficient, 
Portuguese version of PIML

1

2

with the exceptions of item 15 of the Parents Scale and items 22 and 26 of the Peers Scale, which slightly increased the alpha values. Finally, all items correlated significantly with the subscale total score, and all corrected item-total correlations were above .30, with the exception of item 15 of the Parents scale and items 14 , 22, and 26 of the Peers scale.

As presented in Table 4, the strongest correlations within the same scale were between the Trust and Communication subscales (.68 and .71 in the Parents and Peers Scales, respectively); Alienation was only moderately correlated with Trust and Communication. Correlations between the subscales of the two scales were moderate to strong $(.44, .29$, and .51 for Trust, Communication, and Alienation, respectively). Finally, the subscales correlated more strongly with the total score of the scale to which they belonged than with the total score of the other scale.

(Insert Tables 2, 3, and 4)

\section{Gender Differences}

Differences between boys and girls in the PIML subscales and total score were analyzed. In the Parents scale, no significant differences were found, Wilk's lambda $=0.99, F(3,310)=1.12, p=.342, \eta^{2}=.011$. In contrast, a significant multivariate effect was found in the Peers scale, Wilk's lambda $=0.96, F(3,310)=3.99, p$ $=.008, \eta_{\mathrm{p}}^{2}=.037$. As presented in Table 5 , subsequent univariate analyses showed significant differences in the Trust and Communication subscales, with girls reporting higher levels of trust and communication in the relationship with their peers than boys. With respect to the total scores of each scale, univariate analyses showed no significant differences between boys and girls in the Parents scale but a significant difference in the Peers Scale, with girls reporting higher levels of perceived security in the relationship with their peers than boys.

\section{(Insert Table 5)}

\section{Associations between the PIML and Other Measures}

As presented in Table 6, externalizing and internalizing problems were significantly and negatively correlated with trust and communication and significantly and positively correlated with alienation in both scales, with the exception of the correlation between externalizing problems and communication in the Peers scale and the correlation between internalizing problems and communication in the Parents scale, which were not statistically significant. Higher levels of prosocial behavior and quality of life were significantly and positively associated with trust and communication and significantly and negatively associated with alienation in both scales.

(Insert Table 6) 
Portuguese version of PIML

\section{Study 2}

In Study 2, we cross-validated the factor structure of the PIML in a sample of adolescents. In addition, we analyzed the internal consistency of the PIML and explored its convergent validity through examination of its associations with measures of psychological functioning (internalizing and externalizing problems) and of emotion regulation strategies (self-compassion, cognitive reappraisal and expressive suppression).

\section{Method}

\section{Participants}

The sample included 281 adolescents aged between 13 and 19 years $(M=14.83 ; S D=1.44)$, among whom 110 were girls (39.1\%) and 171 were boys (60.9\%). With respect to education level, $150(53.4 \%)$ of the participants were in the $3^{\text {nd }}$ cycle of basic education (grades 7 to 9 ) and $131(46.6 \%)$ were in the secondary school (grades 10-12). To be included in the study, adolescents had to be between 13 and 19 years old, to be able to understand and answer the questionnaires, and to have no serious mental illness or developmental delay.

\section{Procedures}

The sample was collected in public schools $(n=238 ; 84.7 \%)$ and in the general community $(n=43$; $15.3 \%)$ in the north and central regions of Portugal. Several classes of the $3^{\text {rd }}$ cycle of basic education and of the secondary school were randomly selected to participate in the study and the data collection procedures were similar to those described for Study 1. A subsample of 110 adolescents collected in schools (58.2\% girls) with a mean age of 14.75 years $(S D=1.48$; range: $13-19)$ completed additional measures of psychological functioning, self-compassion, and emotion regulation strategies. The remaining adolescents returned the assessment battery incomplete.

\section{Measures} additional measures.

In addition to the PIML and the SDQ, already described in Study 1, adolescents completed two Self-compassion Scale - Short Form. The short form of the Self-Compassion scale (Castilho, PintoGouveia, \& Duarte, 2015; Raes, Pommier, Neff, \& Van Gucht, 2011) was used to assess adolescents' levels of self-compassion. Self-compassion is an adaptive way of self-to-self relating (Gilbert \& Procter, 2006; Neff, 2009) that can be viewed as a positive emotion regulation strategy (Diedrich, Grant, Hofmann, Hiller, \& Berking, 2014) that implies compassion towards the self; acceptance of one's mistakes, failures, and inadequacies; or selfacceptance in moments of suffering (Neff, 2009). The short form of the SCS has 12 items (e.g., "I try to be understanding and patient towards those aspects of my personality I don't like”) rated on a five-point Likert 
Portuguese version of PIML

scale ranging from 1 (almost never) to 5 (almost always) and measures the six components of self-compassion (Self-kindness, Self-judgment, Common Humanity, Isolation, Mindfulness, and Over-identification). After reverse-coding negative items, it is possible to obtain a global measure of self-compassion by estimating the mean of the 12 items, with higher scores indicating higher self-compassion. In the current study, only the total score of self-compassion was used, and an adequate internal consistency value was obtained $(\alpha=.79)$. The original SCS-SF (Raes et al., 2011) has shown good psychometric properties, including adequate reliability ( $\alpha$ for the total score $=.86($ Dutch sample) and $.89($ English sample $))$ and construct validity (convergent and discriminant). In the Portuguese population, the scale revealed adequate internal reliability and convergent validity both among adults (Castilho et al., 2015) and adolescents (Cunha, Xavier, \& Castilho, 2016).

Emotion Regulation Questionnaire for Children and Adolescents. The Emotion Regulation Questionnaire for Children and Adolescents (ERQ-CA; Gullone \& Taffe, 2012) was used to assess two strategies of emotion regulation: (1) Cognitive Reappraisal (i.e., a strategy of cognitive change that implies the redefinition of the situation to change its emotional impact; e.g., "When I'm worried about something, I make myself think about it in a way that helps me feel better"); and (2) Expressive Suppression (i.e., a strategy that implies the inhibition of emotion-expressive behaviors; e.g., "I keep my feelings to myself"). This questionnaire has 10 items rated on a five-point Likert scale ranging from 1 (strongly disagree) to 5 (strongly agree). The total score of each subscale is the sum of the items and ranges from 6 to 30 in the Cognitive Reappraisal subscale (6 items) and from 4 to 20 in the Expressive Suppression subscale (4 items). In the current study, the Cronbach's alpha was .71 in each subscale. The original scale showed adequate internal consistency (Cronbach's alphas were .75 for the Expressive Suppression subscale and .83 for the Cognitive Reappraisal subscale), as well as construct validity (Gullone \& Taffe, 2012).

\section{Data Analyses}

The factor structure of the PIML (a second-order model with three first order factors and a high-order factor of attachment, for each scale) was tested through CFA. To test the exact same structure of Study 1, the same errors were allowed to correlate. No outliers or collinearity problems were detected. Missing data were infrequent (most items were completed by all participants and no item presented more than $0.7 \%$ of missing cases) and were managed by mean substitution (missing scores were replaced by the mean of the subscale of a particular item). To explore the internal consistency of the PIML, Cronbach's alphas were obtained for each subscale and for the total score. Differences between boys and girls in the PIML subscales and total score were 
Portuguese version of PIML

analyzed through multivariate and univariate analyses of variance, respectively. To explore the convergent validity of the scale, correlations between the PIML subscales and total score and other measures were analyzed.

\section{Results}

Before conducting the main analyses, differences in sociodemographic variables and in attachment dimensions between adolescents who were recruited in school settings and in the general community were analyzed. No significant differences were found for adolescents' age, $F(1,279)=1.76, p=.186$, and gender, $\chi^{2}(1)=1.69, p=.193$. Likewise, no significant differences were found in the Parents subscales, Wilk's lambda $=$ $0.995, F(3,277)=0.45, p=.718, \eta_{\mathrm{p}}^{2}=.005$, or in the Peers subscales, Wilk's lambda $=0.994, F(3,277)=0.54$, $p=.654, \eta_{\mathrm{p}}^{2}=.006$. Therefore, the two groups were analyzed together in the subsequent analyses.

\section{Confirmatory Factor Analysis}

Almost none of the items were significantly skewed or highly kurtotic, with the exception of item 19 in the Parents Attachment scale ("I feel scared in my home") and item 17 in the Peers Attachment scale ("I feel scared with my friends"), which presented skewness and kurtosis values above the recommendations (sk $=5.12$ and $\mathrm{ks}=27.31$ in the parents scale; $\mathrm{sk}=4.73$ and $\mathrm{ks}=23.75$ in the peers scale). Since the large majority of the items presented adequate skewness and kurtosis values, the data was considered appropriate to perform the subsequent analyses.

As presented in Table 1, the factor structure of the PIML was replicated in both scales in the sample of adolescents. The CFI (.91 and .90 for Parents and Peers scales, respectively) and RMSEA (.07 for both scales) indices suggest an acceptable model fit for this age group. All first-order factors loaded significantly on the general Parents Attachment Scale (standardized factor loadings were .99 for Trust and Communication; and -.54 for Alienation) and on the general Peer Attachment Scale (standardized factor loadings were .99 for Trust; .86 for Communication; and -.46 for Alienation). Standardized factor loadings for the items ranged from .36 (item 15) to .78 (item 7) in the Parents scale, and from .19 (item 22) to .81 (item 5) in the Peers scale.

\section{Reliability Analyses}

The values for internal consistency were adequate for the Trust and Communication subscales in both the Parents and Peers scales. The values for internal consistency of the Alienation subscale were below the recommended values, particularly in the Peers scale. Specifically, in the Parents scale, the Cronbach's alphas were $.89, .83$, and .69 (Trust, Communication, and Alienation subscales, respectively). In the Peers scale, the Cronbach's alphas were $.91, .77$, and .59 (Trust, Communication, and Alienation subscales, respectively). The Cronbach's alphas for global scores were adequate (.91 in both scales). 
Portuguese version of PIML

\section{Gender Differences}

Differences between boys and girls in the PIML subscales were analyzed. A significant multivariate effect was found in the Parents scale, Wilk's lambda $=0.96, F(3,277)=4.18, p=.006, \eta_{\mathrm{p}}^{2}=.043$, as well as in the Peers scale, Wilk's lambda $=0.95, F(3,277)=4.43, p=.005, \eta_{\mathrm{p}}^{2}=.046$. As presented in Table 5, subsequent univariate analyses showed that boys reported higher levels of trust and communication in the relationship with their parents than girls. In the relationship with peers, boys presented higher levels of alienation and lower levels of communication than girls. With respect to the total scores of each scale, univariate analyses showed significant differences between boys and girls in both the Parents and Peers scales, with boys reporting higher levels of perceived security in the relationship with their parents than girls and girls reporting higher levels of perceived security in the relationship with their peers than boys.

\section{Associations between the PIML Subscales and Other Measures}

As presented in Table 7, externalizing and internalizing problems were negatively and significantly correlated with trust and communication and positively and significantly correlated with alienation in both scales, with the exception of the correlation between externalizing problems and communication in the Peers scale, which was not statistically significant. Higher levels of self-compassion were positively associated with the Trust and Communication subscales in the Parents scale and with the Trust subscale in the Peers scale and negatively associated with the Alienation subscale in both scales. With respect to the emotion regulation strategies, whereas cognitive reappraisal did not correlate significantly with any subscale, higher levels of expressive suppression were found to be negatively correlated with Trust and Communication and negatively correlated with Alienation in both scales.

\section{(Insert Table 7)}

\section{Discussion}

The results of this study demonstrate that the Portuguese version of the PIML is an adequate measure of children's representations of their relationship with parents and peers and therefore of their affective-cognitive experiences in the relationship with these attachment figures. Evidence of the PIML's reliability, validity, and cultural adequacy was obtained in this study.

The Portuguese PIML questionnaire retained the original factor structure, composed of a second-order factor of attachment and three first-order factors (trust, communication, and alienation) in both scales. The Delinquency subscale was excluded from the questionnaire because it did not load significantly on the peer attachment factor. In addition, two of its three items were not normally distributed. This subscale is not directly 
Portuguese version of PIML

1 related to the construct of peer attachment, as clarified by Ridenour et al. (2006); therefore, its exclusion does not affect the instrument's construct validity. Notably, the Delinquency subscale was also eliminated in the Colombian validation of the PIML (Camargo, Mejía, Herrera, \& Carrillo, 2007) because of its low internal consistency and low correlations with the other subscales. The factor structure found in Study 1 was replicated in Study 2 in a cross-validation sample composed of adolescents aged between 13 and 19 years, which supports the utilization of the PIML in different age groups (from 8 to 18 years old). These results support the use of the subscales scores for assessing different aspects of children's affective-cognitive experiences in the relationship with their parents and peers, as well as the use of a total attachment score.

The Portuguese version of the PIML proved to be a reliable measure of attachment. Consistent with the results obtained in the original and Colombian studies (Camargo et al., 2007; Ridenour et al., 2006), adequate Cronbach's alphas were obtained for the total scores and for the Trust and Communication subscales (above .70) in both the child and adolescent samples. The Alienation subscale presented Cronbach's alphas coefficients that are lower than the recommended values, which is consistent with the previous validation studies of the PIML (Camargo et al., 2007; Ridenour et al., 2006) as well as with the validation studies of the IPPA (Guarnieri, Ponti, \& Tani, 2010; Gullone \& Robinson, 2005).

Moreover, the item analyses showed that all items correlated significantly with the corresponding subscale, and almost all corrected item-total correlations were above .30 , with the exception of one item in the Parents scale (item 15) and three items in the Peers scale (items 14, 22 and 26). Additionally, the elimination of items 15 (Parents scale) and items 22 and 26 (Peers scale) resulted in an increase in the Cronbach alpha's coefficient of the corresponding subscale. Interestingly, the same items (except item 26) were excluded from the

21 Colombian PIML version because they also lowered the internal consistency of the subscales. Although the original study did not present the item-total correlations, the factor loadings of these items were low, a result that is consistent with the results obtained in our study, suggesting that these items do not contribute to the construct validity and reliability of the questionnaire. Nevertheless, we decided to maintain these items to leave the questionnaire unchanged and so that future studies with the Portuguese version can be comparable to studies with the original version.

With respect to the intercorrelations between the PIML subscales, in line with previous studies with the PIML (Camargo et al., 2007; Ridenour et al., 2006) and also with the IPPA (e.g., Gullone \& Robinson, 2005), the highest correlations were found between Trust and Communication within each scale because they both represent positive affective/cognitive experiences with the attachment figures. The Alienation subscale 
Portuguese version of PIML

1 correlated negatively and moderately with these subscales because it represents negative affective/cognitive experiences with the attachment figures. Moreover, the Trust and Communication subscales presented stronger correlations with the total attachment score and higher factor loadings on the total attachment factor than the Alienation subscale. These results may suggest that the Trust and Communication subscales provide better representations of the construct this instrument intends to measure than the Alienation subscale. According to Ridenour et al. (2006), the Alienation subscale may more strongly reflect "characteristics of the person other than the respondent in the relationship" (p. 1049) than the other two subscales. Nevertheless, the multidimensional structure of the PIML was confirmed in the present and previous studies and should be maintained to allow for a more comprehensive examination of attachment (in)security in this developmental phase.

Significant differences were found between boys and girls in several subscales. Among children, we found that girls reported higher levels of trust, communication, and overall attachment to peers than boys, and no significant differences were found in the parents subscales. Among adolescents, girls also reported higher levels of communication and overall attachment to peers than boys and lower levels of alienation. In the Parents scale, we found an inverse pattern of results, with boys presenting higher levels of trust, communication and overall attachment to parents than girls. These results are in line with previous findings (Gullone \& Robinson, 2005; Pace, San Martini, \& Zavattini, 2011; Ridenour et al., 2006) suggesting that whereas boys tend to present more positive representations of their relationship with their parents, girls tend to present more positive representations of their relationship with their peers. Although it is not possible to ascertain whether this difference is caused by a different response style or to a real difference in attachment relationships, the consistency of these differences

21 in several studies suggest that there is a gender effect in the way children and adolescents perceive their relationships with parents and friends. Girls appear to establish more secure relationships with their friends, reporting more trust in their accessibility and responsiveness, higher levels of mutual communication and, during adolescence, less negative affective-cognitive experiences. This finding is consistent with previous studies showing that girls, compared to boys, are more relationship-oriented, tend to care more about and to be more engaged with their friendships, and are more likely to seek support from peers and to self-disclosure with their friends (Rose \& Rudolph, 2006). Moreover, these results may reflect an earlier disengagement from parental relationships with a subsequent higher investment in peer relationships in girls, as suggested by Pace et al. (2011). 
Portuguese version of PIML

As expected, significant correlations were found between the PIML subscales and total scores and several indicators of psychosocial adjustment and emotion regulation strategies. Overall, a more positive perception of the relationship with attachment figures was associated with lower levels of internalizing and externalizing problems, higher levels of prosocial behavior, and better quality of life. This finding is in line with the results of previous studies (Gallarin \& Alonso-Arbiol, 2013; Guarnieri et al., 2010; Kerns \& Brumariu, 2014; Ridenour et al., 2006) and corroborates the assumption that a secure attachment plays a key role in children's and adolescents' psychological adjustment, as well as in their social and emotional development (Ainsworth et al., 1978; Bowlby, 1969/1982). Additionally, our results showed that more positive representations of the relationship with parents and peers were associated with higher levels of self-compassion and lower levels of expressive suppression. In fact, it has been suggested that self-compassion emerges in the context of a secure relationship with attachment figures (Gilbert \& Procter, 2006) because these early experiences of care promote the development of emotional memories of being soothed and protected, which in turn allows the individual to learn how to regulate the emotions with affection, warmth, and care when needed. Even though self-compassion has been scarcely studied in adolescence, previous studies with adult populations have shown that higher levels of attachment security are associated with higher levels of self-compassion (Moreira, Gouveia, Carona, Silva, \& Canavarro, 2015), and it appears that the same processes may explain the associations found in this study. Similarly, we found that expressive suppression, a strategy of emotion regulation that consists in the inhibition of emotion-expressive behavior, was associated with lower levels of trust and communication and higher levels of alienation in both scales. This result is consistent with attachment theory, which postulates that secure attachment involves the development of adaptive emotion regulation strategies, whereas insecure attachment promotes the development of secondary strategies characterized by avoidance or ambivalence (Cassidy, 1994; Mikulincer \& Shaver, 2007).

The current study has some limitations that should be noted. First, although we managed to obtain an equal number of boys and girls in Study 1, in Study 2 the representativeness of the sample may have been compromised because of the higher number of boys $(60.9 \%)$. Second, we were not able to determine the testretest reliability of the PIML because the assessment protocol was only administered once. Third, the exclusive use of self-report measures, particularly for assessing attachment, has introduced a mono-method bias. In future studies, it would be interesting to use other methods to assess children's attachment representations and to explore the degree of convergence between both. Fourth, other self-report measures of attachment would have been useful to test the convergent validity of the scale. However, there are no other self-report measures to assess 
Portuguese version of PIML

1 attachment representations in middle childhood validated for the Portuguese population, which also underlines

2 the relevance of the present study. Fifth, although parents were informed that they could not influence the

3 answers of their children if they help them understand the items of the questionnaires, we cannot guarantee that

4 children's responses were not influenced by the fact that they have completed the questionnaires at home. Sixth,

5 although adequate Cronbach's alphas were found for the total score of the Parents and Peers scales in both

6 studies (above .80) and for most subscales (Cronbach's alphas ranged from .73 to .91), the Alienation subscale

7 presented a Cronbach' alpha value below the recommendations in both studies (.66 for both Parents and Peers

8 scales in Study 1;.69 and .59 for Parents and Peers scales, respectively, in Study 2). Therefore, the Alienation

9 subscale is not suitable for individual measurement.

10 Despite these limitations, this study represents an important contribution to the measurement of

11 attachment security in middle childhood. Our study corroborated that attachment in middle childhood and

12 adolescence can be reliably measured in terms of the dimensions of trust, communication, and alienation, which

13 supports the studies conducted to date with the IPPA. The Portuguese version of the PIML proved to be a

14 psychometrically sound measure of children's representations of attachment relationships and it was shown to be

15 adequate for children aged between 8 and 12 years, as well as for adolescents aged up to 18 years. 
Portuguese version of PIML

\section{References}

Ainsworth, M. (1979). Infant-mother attachment. American Psychologist, 34(10), 935-937. doi:10.1037/0003066X.34.10.932

Ainsworth, M., Blehar, M., Waters, E., \& Wall, S. (1978). Patterns of Attachment. Hillsdale, NJ: Erlbaum.

Armsden, G. C., \& Greenberg, M. T. (1987). The Inventory of Parent And Peer Attachment: Individual differences and their relationship to psychological well-being in adolescence. Journal of Youth and Adolescence, 16(5), 427-454. doi:10.1007/bf02202939

Bowlby, J. (1969/1982). Attachment. Vol. 1: Attachment and Loss. London: The Hogarth Press.

Bretherton, I., \& Munholland, K. A. (1999). Internal working models in attachment relationships: A construct revisited. In J. Cassidy, \& P. R. Shaver (Eds.), Handbook of attachment: Theory, research, and clinical applications (pp. 89-111). New York: The Guilford Press.

Brown, T. A. (2006). Confirmatory factor analysis for applied research. New York: The Guilford Press.

Browne, M. W., \& Cudeck, R. (1993). Alternative ways of assessing model fit. In K. A. Bollen, \& J. S. Long (Eds.), Testing structural equation models (pp. 136-162). Beverly Hills, CA: Sage.

Byrne, B. (2010). Structural equation modeling with AMOS: Basic concepts, applications, and programming (2nd ed.). New York, NY: Taylor \& Francis.

Camargo, S. L., Mejía, G. L., Herrera, A. N., \& Carrillo, S. (2007). Adaptación del cuestionario "Personas en Mi Vida” en niños y niñas bogotanos entre 9 y 12 años de edad. [Adaptation of the People in My Life questionnaire in a sample of Colombian middle-age children]. Acta Colombiana de Psicología, 10(2), $83-93$

Cassidy, J. (1994). Emotion regulation: Influences of attachment relationships. Monographs of the Society for Research in Child Development, 59(2-3), 228-249. doi:10.1111/j.1540-5834.1994.tb01287.x

Castilho, P., Pinto-Gouveia, J., \& Duarte, J. (2015). Evaluating the multifactor structure of the long and short versions of the Self-compassion Scale in a clinical sample. Journal of Clinical Psychology, 71(9), 856870. doi:10.1002/jclp.22187

Cook, E. T., Greenberg, M. T., \& Kusche, C. A. (1995). People in my life: Attachment relationships in middle childhood. Paper presented at the Society for Research in Child Development, Indianapolis, IN.

Crittenden, P. M. (1992). Preschool Assessment of Attachment Manual. Miami, FL: Family Relations Institute. 
Portuguese version of PIML

Cunha, M., Xavier, A., \& Castilho, P. (2016). Understanding self-compassion in adolescents: Validation study of the Self-Compassion Scale. Personality and Individual Differences, 93, 56-62. doi:10.1016/j.paid.2015.09.023

Diedrich, A., Grant, M., Hofmann, S. G., Hiller, W., \& Berking, M. (2014). Self-compassion as an emotion regulation strategy in major depressive disorder. Behavious Research and Therapy, 58, 43-51. doi:10.1016/j.brat.2014.05.006

Fleitlich, B., Loureiro, M., Fonseca, A., \& Gaspar, M. (2005). Questionário de Capacidades e de Dificuldades (SDQ-Por). From http://www.sdqinfo.org

Gallarin, M., \& Alonso-Arbiol, I. (2013). Dimensionality of the Inventory of Parent and Peer Attachment: Evaluation with the Spanish version. The Spanish Journal of Psychology, 16, E55. doi:10.1017/sjp.2013.47

Gilbert, P., \& Procter, S. (2006). Compassionate mind training for people with high shame and self-criticism: Overview and pilot study of a group therapy approach. Clinical Psychology \& Psychotherapy, 13(6), 353-379. doi:10.1002/cpp.507

Goodman, A., Lamping, D. L., \& Ploubidis, G. B. (2010). When to use broader internalising and externalising subscales instead of the hypothesised five subscales on the Strengths and Difficulties Questionnaire (SDQ): Data from British parents, teachers and children. Journal of Abnormal Child Psychology, 38(8), 1179-1191. doi:10.1007/s10802-010-9434-x

Goodman, R. (2001). Psychometric properties of the Strengths and Difficulties Questionnaire. Journal of the American Academy of Child \& Adolescent Psychiatry, 40(11), 1337-1345. doi:10.1097/00004583200111000-00015

Gouveia, M., Frontini, R., Canavarro, M., \& Moreira, H. (2014). Quality of life and psychological functioning in pediatric obesity: The role of body image dissatisfaction between girls and boys of different ages. Quality of Life Research, 23(9), 2629-2638. doi:10.1007/s11136-014-0711-y

Guarnieri, S., Ponti, L., \& Tani, F. (2010). The Inventory of Parent and Peer Attachment (IPPA): A study on the validity of styles of adolescent attachment to parents and peers in an Italian sample. TPM - Testing, Psychometrics, Methodology in Applied Psychology, 17(3), 103-130.

Gullone, E., \& Robinson, K. (2005). The Inventory of Parent and Peer Attachment—Revised (IPPA-R) for children: A psychometric investigation. Clinical Psychology \& Psychotherapy, 12(1), 67-79. doi:10.1002/cpp.433 
Portuguese version of PIML

Gullone, E., \& Taffe, J. (2012). The Emotion Regulation Questionnaire for Children and Adolescents (ERQCA): A psychometric evaluation. Psychological Assessment, 24(2), 409-417. doi:10.1037/a0025777

Hu, L. t., \& Bentler, P. M. (1999). Cutoff criteria for fit indexes in covariance structure analysis: Conventional criteria versus new alternatives. Structural Equation Modeling: A Multidisciplinary Journal, 6(1), 1-55. doi:10.1080/10705519909540118

Kaplan, N., \& Main, M. (1986). A system for the analysis of children's family drawings in terms of attachment. Department of Psychology, University of California. Berkeley.

Kerns, K. A., \& Brumariu, L. E. (2014). Is insecure parent-child attachment a risk factor for the development of anxiety in childhood or adolescence? Child Development Perspectives, 8(1), 12-17. doi:10.1111/cdep.12054

Kline, R. (2011). Principals and practice of structural equation modelling (3rd ed.). New York, NY: The Guildford Press.

Matos, M. G., Gaspar, T., \& Simões, C. (2012). Health-related quality of life in Portuguese children and adolescents. Psicologia: Reflexão e Crítica, 25(2), 230-237. doi:10.1590/S0102-79722012000200004

Mikulincer, M., \& Shaver, P. R. (2007). Attachment in adulthood: Structure, dynamics, and change. New York: The Guilford Press.

Moreira, H., Carona, C., Silva, N., Frontini, R., Bullinger, M., \& Canavarro, M. C. (2013). Psychological and quality of life outcomes in pediatric populations: A parent-child perspective. The Journal of Pediatrics, 163(5), 1471-1478. doi:10.1016/j.jpeds.2013.06.028

Moreira, H., Gouveia, M. J., Carona, C., Silva, N., \& Canavarro, M. C. (2015). Maternal attachment and children's quality of life: The mediating role of self-compassion and parenting stress. Journal of Child and Family Studies, 24(8), 2332-2344. doi:10.1007/s10826-014-0036-z

Neff, K. D. (2009). Self-Compassion. In M. R. Leary \& R. H. Hoyle (Eds.), Handbook of Individual Differences in Social Behavior (pp. 561-573). New York: The Guilford Press.

Pace, C. S., San Martini, P., \& Zavattini, G. C. (2011). The factor structure of the Inventory of Parent and Peer Attachment (IPPA): A survey of Italian adolescents. Personality and Individual Differences, 51(2), 8388. doi:10.1016/j.paid.2011.03.006

Raes, F., Pommier, E., Neff, K., \& Van Gucht, D. (2011). Construction and factorial validation of a short form of the Self-Compassion Scale. Clinical Psychology \& Psychotherapy, 18(3), 250-255. doi:10.1002/cpp.702 
Portuguese version of PIML

1 Ravens-Sieberer, U., Erhart, M., Rajmil, L., Herdman, M., Auquier, P., Bruil, J., . . Kilroe, J. (2010). Reliability,

2

3

4 construct and criterion validity of the KIDSCREEN-10 score: A short measure for children and adolescents' well-being and health-related quality of life. Quality of Life Research, 19(10), 1487-1500. doi:10.1007/s11136-010-9706-5

Ridenour, T. A., Greenberg, M. T., \& Cook, E. T. (2006). Structure and validity of people in my life: A selfreport measure of attachment in late childhood. Journal of Youth and Adolescence, 35(6), 1037-1053. doi:10.1007/s10964-006-9070-5

Rose, A. J., \& Rudolph, K. D. (2006). A review of sex differences in peer relationship processes: Potential tradeoffs for the emotional and behavioral development of girls and boys. Psychological Bulletin, 132(1), 98-131. doi:10.1037/0033-2909.132.1.98

Slough, N. M., \& Greenberg, M. T. (1990). Five-year-olds' representations of separation from parents: Responses from the perspective of self and other. New Directions for Child and Adolescent Development, 1990(48), 67-84. doi:10.1002/cd.23219904806

Waters, E. (1995). The attachment Q-set (version 3.0). In E. Waters, B. E. Vaughn, G. Posada. \& K. KondoIkemura (Eds.), Caregiving, cultural, and cognitive perspectives on secure-base behavior and working models: New growing points of attachment theory and research (Vol. 60, pp. 234-246). Monographs of the Society for Research in Child Development.

West, M., Rose, M. S., Spreng, S., Sheldon-Keller, A., \& Adam, K. (1998). Adolescent attachment questionnaire: A brief assessment of attachment in adolescence. Journal of Youth and Adolescence, 27(5), 661-673. doi:10.1023/a:1022891225542

Wilson, J. M., \& Wilkinson, R. B. (2012). The self-report assessment of adolescent attachment: A systematic review and critique. Journal of Relationships Research, 3, 81-94. doi:doi:10.1017/jrr.2012.7 
Portuguese version of PIML

\section{Compliance with Ethical Standards}

3

4 Ethical approval: All procedures performed in studies involving human participants were in accordance with 5 the ethical standards of the institutional and/or national research committee and with the 1964 Helsinki

6 declaration and its later amendments or comparable ethical standards. In addition, the study was approved by the 7 Portuguese Data Protection Authority and the Board of Directors of the School Units.

8 Conflict of Interest: The authors declare that they have no conflict of interest.

9 Informed consent: Informed consent was obtained from all the parents or legal representatives of children. 
Portuguese version of PIML

Table 1. Goodness of fit statistics for the PIML factor models in Studies 1 and 2

\begin{tabular}{|c|c|c|c|c|c|c|c|c|}
\hline & \multicolumn{8}{|c|}{ Goodness of fit statistics } \\
\hline & \multirow{2}{*}{$\chi^{2}(\mathrm{df})$} & \multirow{2}{*}{$p$} & \multirow{2}{*}{ CFI } & \multirow{2}{*}{ SRMR } & \multirow{2}{*}{ RMSEA } & \multicolumn{2}{|c|}{ RMSEA 90\% CI } & \multirow{2}{*}{ AIC } \\
\hline & & & & & & Low/Hi & $p$ & \\
\hline \multicolumn{9}{|l|}{ Study 1} \\
\hline \multicolumn{9}{|l|}{ Parents } \\
\hline Model 1 & $431.19(168)$ & $<.001$ & .87 & .06 & .07 & $.063 / .079$ & $<.001$ & 515.19 \\
\hline Model 2 & $362.27(163)$ & $<.001$ & .90 & .06 & .06 & $.054 / .071$ & .009 & 456.27 \\
\hline \multicolumn{9}{|l|}{ Peers } \\
\hline Model 1 & $552.18(250)$ & $<.001$ & .88 & .06 & .06 & $.055 / .069$ & .003 & 652.18 \\
\hline Model 2 & $435.00(245)$ & $<.001$ & .93 & .06 & .05 & $.042 / .057$ & .510 & 545.00 \\
\hline \multicolumn{9}{|l|}{ Study 2} \\
\hline \multicolumn{9}{|l|}{ Parents } \\
\hline Model 2 & $395.40(163)$ & $<.001$ & .91 & .06 & .07 & $.062 / .080$ & $<.001$ & 489.40 \\
\hline \multicolumn{9}{|l|}{ Peers } \\
\hline Model 2 & $543.02(245)$ & $<.001$ & .90 & .06 & .07 & $.058 / .073$ & $<.001$ & 653.02 \\
\hline
\end{tabular}


Table 2. Reliability and item analyses for the Parents Attachment Scale in Study 1

\begin{tabular}{|c|c|c|c|c|}
\hline & \\
\hline & Mean $(S D)$ & $\begin{array}{l}\text { Item-total } \\
\text { correlation }\end{array}$ & $\begin{array}{l}\text { Corrected } \\
\text { item-total } \\
\text { correlation }\end{array}$ & $\begin{array}{c}\text { Cronbach's } \\
\text { alpha if } \\
\text { item deleted }\end{array}$ \\
\hline \multicolumn{5}{|l|}{ Trust $(\alpha=.85)$} \\
\hline 1. My parents respect my feelings. & $3.37(0.79)$ & $.60 * *$ & .45 & .85 \\
\hline 3. My parents accept me as I am. & $3.70(0.60)$ & $.65 * *$ & .55 & .84 \\
\hline 4. My parents understand me. & $3.39(0.75)$ & $.64 * *$ & .51 & .85 \\
\hline 5. My parents care about me. & $3.80(0.49)$ & $.71 * *$ & .65 & .83 \\
\hline 6. I trust my parents. & $3.73(0.57)$ & $.69 * *$ & .60 & .84 \\
\hline $\begin{array}{l}\text { 7. I can count on my parents to help me when I } \\
\text { have a problem. }\end{array}$ & $3.72(0.57)$ & $.77 * *$ & .70 & .83 \\
\hline 13. My home is a nice place to live. & $3.81(0.47)$ & $.60 * *$ & .52 & .84 \\
\hline 14. My parents pay attention to me. & $3.66(0.57)$ & $.66^{* *}$ & .57 & .84 \\
\hline 20. I get along well with my parents. & $3.68(0.64)$ & $.73 * *$ & .64 & .83 \\
\hline 21. My parents are proud of the things I do. & $3.54(0.71)$ & $.63 * *$ & .51 & .84 \\
\hline \multicolumn{5}{|l|}{ Communication $(\alpha=.74)$} \\
\hline 2. My parents listen to what I have to say. & $3.27(0.80)$ & $.64 * *$ & .42 & .73 \\
\hline $\begin{array}{l}\text { 8. My parents can tell when I am upset about } \\
\text { something. }\end{array}$ & $3.36(0.77)$ & $.66^{* *}$ & .46 & .71 \\
\hline $\begin{array}{l}\text { 9. I talk to my parents when I am having a } \\
\text { problem. }\end{array}$ & $3.26(0.84)$ & $.77 * *$ & .60 & .65 \\
\hline $\begin{array}{l}\text { 10. If my parents know that something is } \\
\text { bothering me, they ask me about it. }\end{array}$ & $3.49(0.72)$ & $.70 * *$ & .53 & .69 \\
\hline $\begin{array}{l}\text { 11. I share my thoughts and feelings with my } \\
\text { parents. }\end{array}$ & $3.11(0.88)$ & $.73 * *$ & .52 & .69 \\
\hline \multicolumn{5}{|l|}{ Alienation $(\alpha=.66)$} \\
\hline $\begin{array}{l}\text { 15. My parents don't understand what I am } \\
\text { going through these days. }\end{array}$ & $2.12(1.18)$ & $.60 * *$ & .25 & .71 \\
\hline 16. I get upset easily with my parents. & $1.76(0.91)$ & $.68 * *$ & .46 & .59 \\
\hline 17. I feel angry with my parents. & $1.41(0.75)$ & $.71 * *$ & .54 & .56 \\
\hline 18. It's hard for me to talk to my parents. & $1.61(0.96)$ & $.70 * *$ & .47 & .58 \\
\hline 19. I feel scared in my home. & $1.32(0.76)$ & $.64 * *$ & .45 & .60 \\
\hline Parents Attachment Scale $(\alpha=$ & & & & \\
\hline
\end{tabular}

$* * p<.01$ 
Table 3. Reliability and item analyses for the Peers Attachment Scale in Study 1

\begin{tabular}{|c|c|c|c|c|}
\hline & \\
\hline & Mean $(S D)$ & $\begin{array}{l}\text { Item-total } \\
\text { correlation }\end{array}$ & $\begin{array}{l}\text { Corrected } \\
\text { item-total } \\
\text { correlation }\end{array}$ & $\begin{array}{c}\text { Cronbach's } \\
\text { alpha if item } \\
\text { deleted }\end{array}$ \\
\hline \multicolumn{5}{|l|}{ Trust $(\alpha=.89)$} \\
\hline 1. My friends respect my feelings. & $2.97(0.87)$ & $.62 * *$ & .53 & .89 \\
\hline 2. My friends listen to what I have to say. & $3.03(0.85)$ & $.70 * *$ & .63 & .88 \\
\hline 3. My friends accept me as I am. & $3.36(0.80)$ & $.71 * *$ & .64 & .88 \\
\hline 4. My friends understand me. & $3.15(0.84)$ & $.72 * *$ & .65 & .88 \\
\hline 5. My friends care about me. & $3.13(0.88)$ & $.75^{* *}$ & .68 & .88 \\
\hline 6. I trust my friends. & $3.46(0.77)$ & $.71 * *$ & .64 & .88 \\
\hline $\begin{array}{l}\text { 7. I can count on my friends to help me when I } \\
\text { have a problem. }\end{array}$ & $3.32(0.82)$ & $.74 * *$ & .68 & .88 \\
\hline 12. I like to be with my friends. & $3.73(0.54)$ & $.63 * *$ & .57 & .89 \\
\hline 13. My friends pay attention to me. & $2.80(0.91)$ & $.69 * *$ & .61 & .88 \\
\hline 19. I get along well with my friends. & $3.61(0.69)$ & $.61 * *$ & .53 & .89 \\
\hline 20. My friends are proud of the things I do. & $2.94(0.89)$ & $.71 * *$ & .64 & .88 \\
\hline $\begin{array}{l}\text { 27. My parents like and approve of my } \\
\text { friends. }\end{array}$ & $3.53(0.70)$ & $.55^{* *}$ & .47 & .89 \\
\hline \multicolumn{5}{|l|}{ Communication $(\alpha=.73)$} \\
\hline $\begin{array}{l}\text { 8. My friends can tell when I am upset about } \\
\text { something. }\end{array}$ & $3.00(0.94)$ & $.78 * *$ & .63 & .63 \\
\hline $\begin{array}{l}\text { 9. I talk to my friends when I am having a } \\
\text { problem. }\end{array}$ & $2.86(0.98)$ & $.77 * *$ & .60 & .63 \\
\hline $\begin{array}{l}\text { 10. If my friends know that something is } \\
\text { bothering me, they ask me about it. }\end{array}$ & $3.03(0.93)$ & $.78 * *$ & .62 & .63 \\
\hline $\begin{array}{l}\text { 11. I share my thoughts and feelings with my } \\
\text { friends. }\end{array}$ & $2.75(1.00)$ & $.73 * *$ & .53 & .66 \\
\hline $\begin{array}{l}\text { 26. Doing well at school is important to my } \\
\text { friends. }\end{array}$ & $3.08(1.05)$ & $.43 * *$ & .13 & .81 \\
\hline \multicolumn{5}{|l|}{ Alienation $(\alpha=.66)$} \\
\hline $\begin{array}{l}\text { 14. My friends don't understand what I am } \\
\text { going through these days. }\end{array}$ & $1.99(0.99)$ & $.49 * *$ & .25 & .66 \\
\hline 15. I get upset easily with my friends. & $1.68(0.86)$ & $.62 * *$ & .44 & .60 \\
\hline 16. I feel angry with my friends. & $1.41(0.72)$ & $.62 * *$ & .47 & .60 \\
\hline 17. I feel scared with my friends. & $1.29(0.72)$ & $.65 * *$ & .50 & .59 \\
\hline 18 It's hard for me to talk to my friends. & $1.61(0.95)$ & $.70 * *$ & .52 & .57 \\
\hline $\begin{array}{l}\text { 21. I think my friends are a bad influence on } \\
\text { me. }\end{array}$ & $1.43(0.80)$ & $.54 * *$ & .36 & .62 \\
\hline 22. I wish I had more friends. & $2.80(1.18)$ & $.49 * *$ & .18 & .70 \\
\hline
\end{tabular}

Peers Attachment Scale $(\alpha=.88)$

$* * p<.01$ 
Portuguese version of PIML

Table 4. Correlations between the PIML subscales and total scores in Study 1

\begin{tabular}{|c|c|c|c|c|c|c|c|}
\hline & 1 & 2 & 3 & 4 & 5 & 6 & 7 \\
\hline 1. Trust_parents & --- & & & & & & \\
\hline 2. Communication_parents & $.68 * *$ & --- & & & & & \\
\hline 3. Alienation_parents & $-.28 * *$ & $-.24 *$ & --- & & & & \\
\hline 4. Trust_peers & $.44 * *$ & $.38 * *$ & $-.28 * *$ & --- & & & \\
\hline 5. Communication_peers & $.25 * *$ & $.29 * *$ & $-.15 * *$ & $.71 * *$ & --- & & \\
\hline 6. Alienation_peers & $-.12 *$ & -.06 & $.51 * *$ & $-.35 * *$ & $-.21 * *$ & --- & \\
\hline 7. Total attachment parents & $.88 * *$ & $.81 * *$ & $-.62 * *$ & $.48 * *$ & $.29 * *$ & $-.28 * *$ & --- \\
\hline 8. Total attachment peers & $.38 * *$ & $.33 * *$ & $-.38 * *$ & $.93 * *$ & $.80 * *$ & $-.60 * *$ & $.47 * *$ \\
\hline
\end{tabular}


Portuguese version of PIML

Table 5. Means and standards deviations for the PIML questionnaire subscales and gender comparisons in Studies 1 and 2

\begin{tabular}{|c|c|c|c|c|c|}
\hline \multirow[b]{3}{*}{ Study 1 - Children } & \multirow{2}{*}{$\begin{array}{l}\text { Overall } \\
\text { sample }\end{array}$} & \multirow{2}{*}{$\begin{array}{c}\text { Boys } \\
M(S D)\end{array}$} & \multirow{2}{*}{$\begin{array}{c}\text { Girls } \\
M(S D)\end{array}$} & \multicolumn{2}{|c|}{ Gender comparisons } \\
\hline & & & & \multirow{2}{*}{$F / p$} & \multirow{2}{*}{ Cohen's d } \\
\hline & $N=314$ & $n=159$ & $n=155$ & & \\
\hline \multicolumn{6}{|l|}{ Parents } \\
\hline Trust & $36.39(4.08)$ & $36.20(4.18)$ & $36.60(3.99)$ & $0.77 / .381$ & 0.10 \\
\hline Communication & $16.49(2.80)$ & $16.39(2.80)$ & $16.60(2.82)$ & $0.44 / .508$ & 0.07 \\
\hline Alienation & $8.24(3.00)$ & $8.53(3.12)$ & $7.92(2.85)$ & $3.22 / .074$ & 0.20 \\
\hline Total score & $69.65(7.76)$ & $69.05(7.79)$ & $70.27(7.76)$ & $1.95 / .164$ & 0.16 \\
\hline \multicolumn{6}{|l|}{ Peers } \\
\hline Trust & $39.02(6.51)$ & $38.08(6.74)$ & $39.98(6.14)$ & $6.79 / .010$ & 0.29 \\
\hline Communication & $14.72(3.39)$ & $14.09(3.41)$ & $15.36(3.25)$ & $11.34 / .001$ & 0.38 \\
\hline Alienation & $12.19(3.61)$ & $12.49(3.71)$ & $11.89(3.48)$ & $2.18 / .141$ & 0.17 \\
\hline Total score & $76.54(10.93)$ & $74.69(11.02)$ & $78.45(10.53)$ & $9.58 / .002$ & 0.35 \\
\hline Study 2 - Adolescents & $N=281$ & $n=110$ & $n=171$ & & \\
\hline \multicolumn{6}{|l|}{ Parents } \\
\hline Trust & $34.45(5.27)$ & $35.74(4.24)$ & $33.63(5.71)$ & $11.11 / .001$ & 0.42 \\
\hline Communication & $14.63(3.45)$ & $15.41(3.01)$ & $14.13(3.62)$ & $9.52 / .002$ & 0.38 \\
\hline Alienation & $8.12(2.74)$ & $7.99(2.94)$ & $8.21(2.61)$ & $0.43 / .513$ & 0.08 \\
\hline Total score & $65.96(9.79)$ & $68.15(7.99)$ & $64.54(10.57)$ & $9.39 / .002$ & 0.28 \\
\hline \multicolumn{6}{|l|}{ Peers } \\
\hline Trust & $39.24(6.26)$ & $38.42(6.88)$ & 39.77 (5.79) & $3.15 / .077$ & 0.21 \\
\hline Communication & $14.78(3.17)$ & $14.05(3.40)$ & $15.25(2.92)$ & $9.90 / .002$ & 0.38 \\
\hline Alienation & $10.27(2.66)$ & $10.69(3.19)$ & $10.01(2.21)$ & $4.51 / .035$ & 0.25 \\
\hline Total score & $78.74(10.23)$ & $76.77(11.22)$ & $80.01(9.35)$ & $6.85 / .009$ & 0.31 \\
\hline
\end{tabular}


Portuguese version of PIML

Table 6. Correlations between the PIML questionnaire and other measures in Study 1

\begin{tabular}{lcccc}
\cline { 2 - 4 } & $\begin{array}{c}\text { Externalizing } \\
\text { problems }\end{array}$ & $\begin{array}{c}\text { Internalizing } \\
\text { problems }\end{array}$ & $\begin{array}{c}\text { Prosocial } \\
\text { behavior }\end{array}$ & $\begin{array}{c}\text { Quality of } \\
\text { life }\end{array}$ \\
\hline Parents & $-.24^{* *}$ & $-.24^{* *}$ & $.24 * *$ & $.46^{* *}$ \\
Trust & $-.16^{* *}$ & .07 & $.22^{* *}$ & $.35^{* *}$ \\
Communication & $.43^{* *}$ & $.39^{* *}$ & $-.25^{* *}$ & $-.40^{* *}$ \\
Alienation & $-.36^{* *}$ & $-.31^{* *}$ & $.30^{* *}$ & $.53^{* *}$ \\
Total score & & & & $.34^{* *}$ \\
Peers & $-.28^{* *}$ & $-.36^{* *}$ & $.35^{* *}$ & $.20^{* *}$ \\
Trust & -.06 & $-.16^{*}$ & $-.21^{* *}$ & $-.16^{*}$ \\
Communication & $.41^{*}$ & $.43^{* *}$ & $.38^{* *}$ & $.35^{* *}$ \\
Alienation & $-.34^{* *}$ & $-.41^{* *}$ & & \\
Total score & & & & \\
\hline Note. $N=177$ & & & & \\
$* p<.05, * * p<.01$ & & & & \\
\hline
\end{tabular}


Portuguese version of PIML

Table 7. Correlations between the PIML questionnaire and other measures in Study 2

\begin{tabular}{|c|c|c|c|c|c|}
\hline & $\begin{array}{c}\text { Externalizing } \\
\text { problems }\end{array}$ & $\begin{array}{c}\text { Internalizing } \\
\text { problems }\end{array}$ & $\begin{array}{c}\text { Self- } \\
\text { compassion }\end{array}$ & $\begin{array}{c}\text { Cognitive } \\
\text { reappraisal }\end{array}$ & $\begin{array}{c}\text { Expressive } \\
\text { suppression }\end{array}$ \\
\hline \multicolumn{6}{|l|}{ Parents } \\
\hline Trust & $-.33 * *$ & $-.44 * *$ & $.46^{* *}$ & -.05 & $-.30 * *$ \\
\hline Communication & $-.35 * *$ & $-.23 * *$ & $.45 * *$ & .02 & $-.32 * *$ \\
\hline Alienation & $.35^{* *}$ & $.23 *$ & $-.43 * *$ & -.00 & $.20 *$ \\
\hline Total score & $-.38 * *$ & $-.38 * *$ & $.51 * *$ & .03 & $-.32 * *$ \\
\hline \multicolumn{6}{|l|}{ Peers } \\
\hline Trust & $-.33 * *$ & $-.53 * *$ & $.38 * *$ & .12 & $-.48 * *$ \\
\hline Communication & -.07 & $-.26 * *$ & .16 & .10 & $-.27 * *$ \\
\hline Alienation & $.29 *$ & $.19^{*}$ & $-.21 *$ & -.03 & $.22 *$ \\
\hline Total score & $-.29 * *$ & $-.45 * *$ & $.33 * *$ & .11 & $-.43 * *$ \\
\hline \multicolumn{6}{|l|}{ Note. $N=110$} \\
\hline$* p<.05, * * p<.01$ & & & & & \\
\hline
\end{tabular}


Portuguese version of PIML

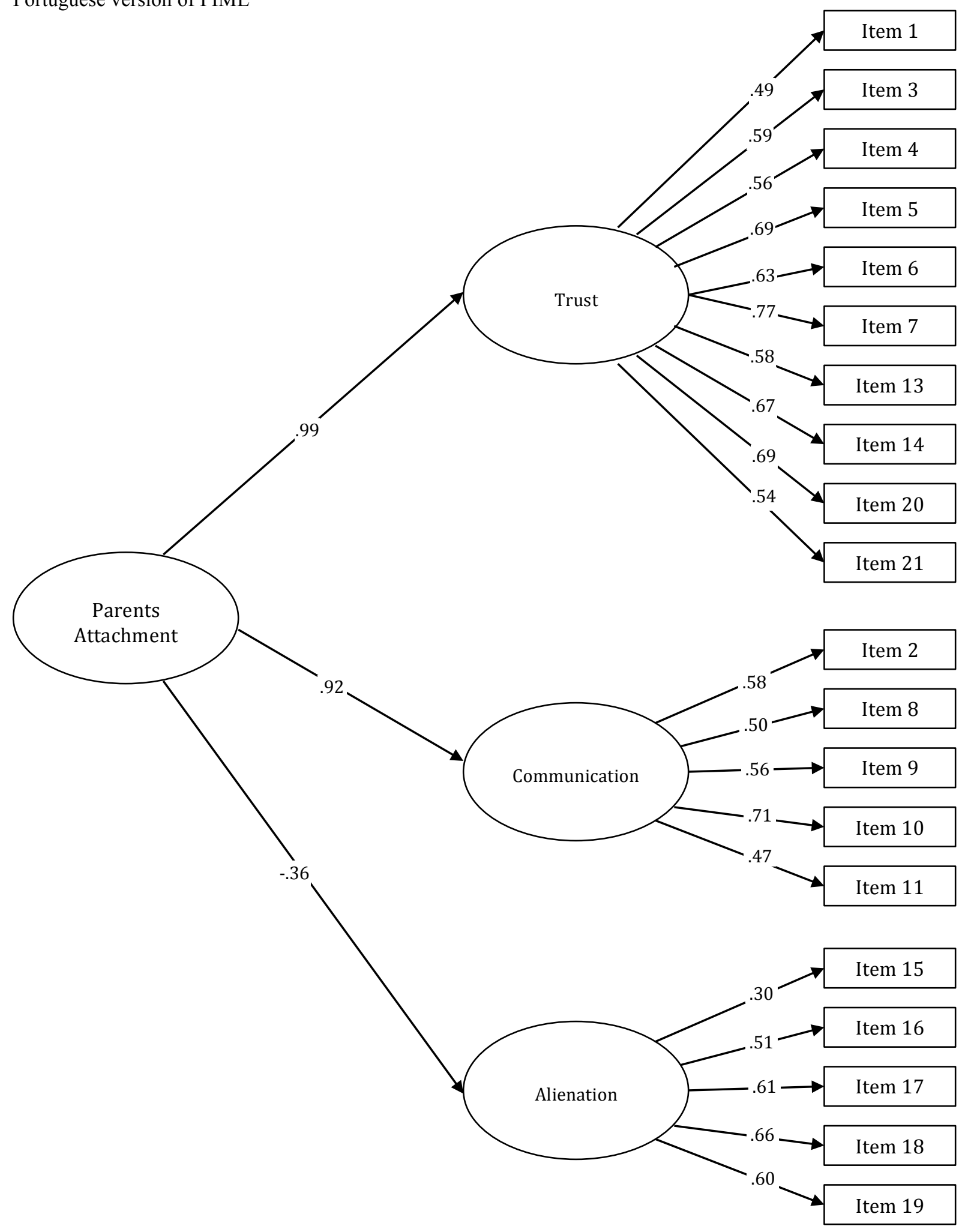

Figure 1. Factor structure of the Parents Attachment Scale in Study 1 


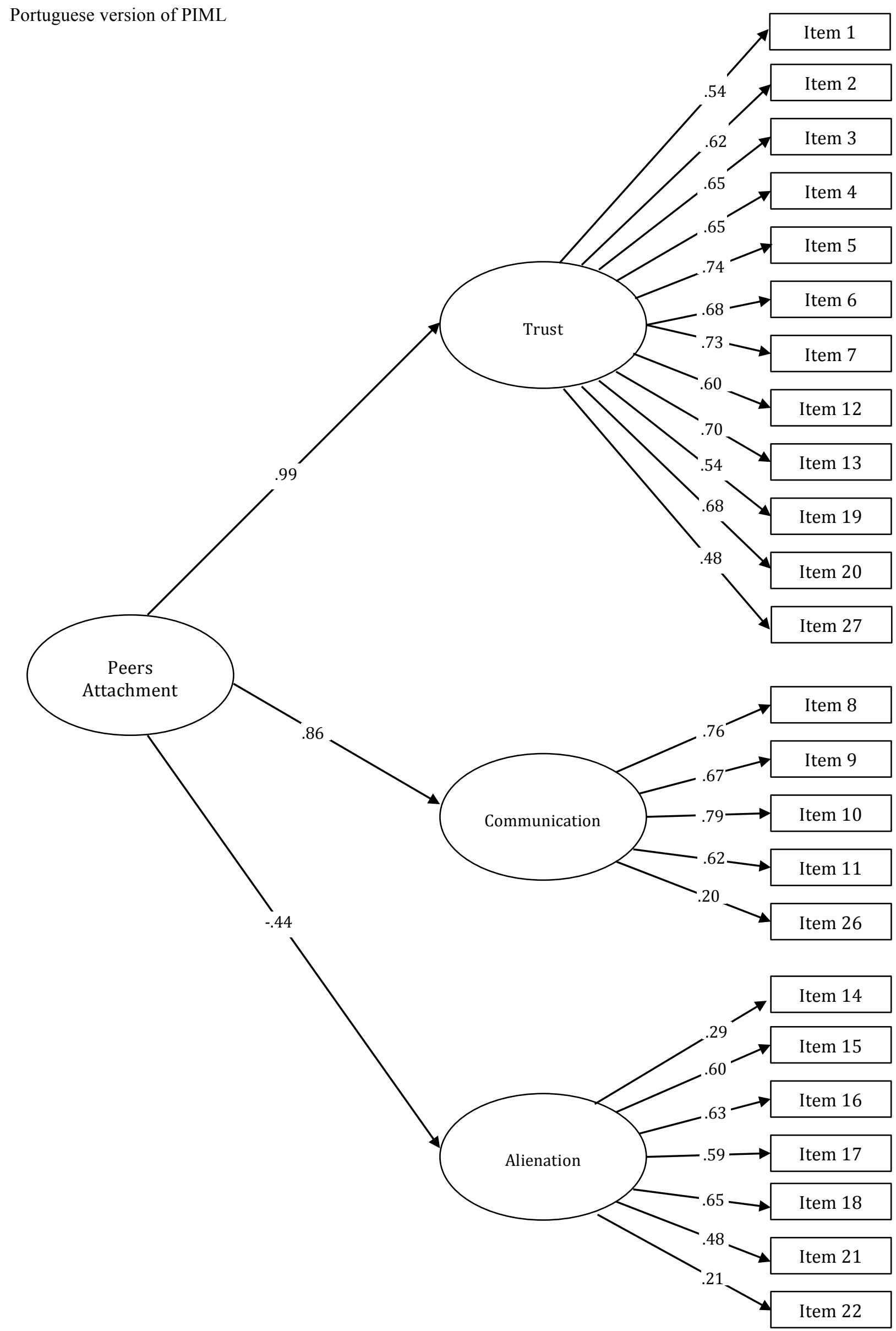

Figure 2. Factor structure of the Peers Attachment Scale in Study 1 
Portuguese version of PIML

\section{Figure captions for Figures 1 and 2}

Note. All standardized regression weights of factor loadings were significant $(p<.001)$. For simplicity, the $p$ values of the regression weights and measurement error terms are not shown. 